\title{
Crimean-Congo haemorrhagic fever outbreak investigation in the Western Region of Afghanistan in 2008
}

\author{
J. Mofleh ${ }^{7}$ and A.Z. Ahmad ${ }^{7}$
}

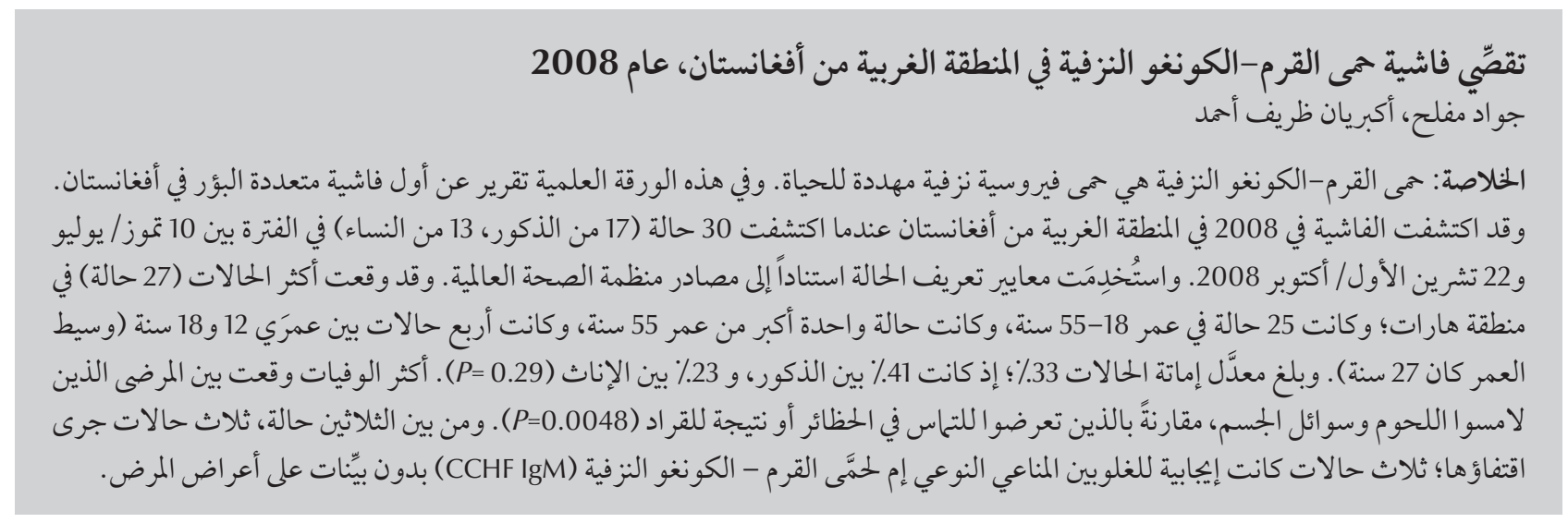

ABSTRACT Crimean-Congo haemorrhagic fever (CCHF) is a life-threatening viral haemorrhagic fever. This paper reports on the first multifocal outbreak recorded in the Afghanistan. The outbreak was detected in 2008 in the Western Region of the country and 30 cases (17 males and 13 females) were detected between 10 July and 22 October 2008. Standard case definitions based on World Health Organization sources were used. Most of the cases (27) occurred in Herat province; 25 were aged between 18-55, 1 was $>55$ years and 4 were12-18 years (median age was 27 years). The case fatality rate was 33\%; $41 \%$ among males and $23 \%$ among females $(P=0.29$ ). Significantly more patients infected by contact with meat and body fluids died that those whose contact was through animal husbandry or ticks $(P=0.0048)$. Of the 30 cases, 33 close contacts were traced; 3 were positive for CCHF IgM with no symptomatic evidence of the disease.

\section{Investigation de la flambée de fièvre hémorragique de Crimée-Congo dans la région ouest de l'Afghanistan en 2008}

RÉSUMÉ La fièvre hémorragique de Crimée-Congo est une fièvre hémorragique virale qui engage le pronostic vital. Le présent article traite de la première flambée à foyers multiples enregistrée en Afghanistan. La flambée a été détectée en 2008 dans la région ouest du pays et 30 cas ( 17 hommes et 13 femmes) ont été dépistés entre le 10 juillet et le 22 octobre 2008. Les définitions normalisées des cas établies par l'Organisation mondiale de la Santé ont été utilisées. La plupart des cas (27) étaient situés dans la province d'Herât ; 25 patients étaient âgés de 18 à 55 ans, un patient avait plus de 55 ans et 4 patients avaient entre 12 et 18 ans (âge médian 27 ans). Le taux de létalité était de $33 \%$ : $41 \%$ chez les hommes et $23 \%$ chez les femmes $(P=0,29)$. La mortalité des patients infectés par contact avec de la viande ou des fluides corporels était nettement plus élevée que celle des patients ayant contracté la maladie par des animaux d'élevage ou des tiques $(\mathrm{P}=0,0048)$. À partir des 30 cas, 33 contacts rapprochés ont été suivis ; les analyses de trois d'entre eux étaient positives pour les IgM spécifiques de la fièvre hémorragique de Crimée-Congo malgré l'absence de symptômes de la maladie. 


\section{Introduction}

Crimean-Congo haemorrhagic fever (CCHF) is a severe vector-borne viral haemorrhagic fever. The causative agent belongs to the genus Nairovirus in the Bunyaviridae family. Infection is transmitted to humans by Hyalomma ticks or by direct contact with the blood or tissues of infected humans or viraemic livestock [1]. It is primarily a zoonosis which sporadically causes cases and outbreaks of CCHF in humans. CCHF infects a wide range of domestic and wild animals. A seroprevalence rates of $13 \%-36 \%$ have been reported in animals $[2,3]$.The geographical distribution of the virus, like that of its tick vector, is widespread; Africa, Asia, the Middle East and Eastern Europe [4,5]. CCHF is mainly found in rural areas and transmission is associated with poverty and poor medical facilities [6].

The disease has a sudden onset of fever, malaise, weakness, irritability and headache, and severe limb and loin pain. Patients have marked anorexia. Vomiting, abdominal pain and diarrhoea occasionally occur. Face and chest flushes and conjunctival injection are reported at the early stages of the disease development. Haemorrhagic symptoms include enanthem of soft palate, uvula and pharynx, and a fine petechial rash spreading over the chest, abdomen and rest of the body; sometimes large purpuric areas are reported. In serious and fatal cases, bleeding from the gums, nose, lungs, uterus and intestine are reported; these manifestations are often associated with severe liver damage. Haematuria and albuminuria are common but usually not severe [5]. Blood oozing is not uncommon [6]. Fever is constantly elevated from 5 to 12 days or may be biphasic [5]. Other findings are leukopenia with marked lymphopenia. Thrombocytopenia is common.

The case fatality rate is reported to be about $30 \%$ [4] but ranges of $2 \%-70 \%$ have been reported [6-8]. Most of the fatalities occur 5-14 days after onset of the disease [5].

The disease has the potential for nosocomial spread [5]; hospital transmission of disease is well documented in the Islamic Republic of Iran [6].

Early diagnosis of CCHF is important for case management and protection of medical staff. Convalescence is prolonged $[1,2]$.

Supportive therapy is the cornerstone of treatment [4] as no specific treatment is available. A systematic review and meta-analysis found that studies conducted on CCHF and the use of ribavirin were heavily confounded, and the one trial carried out had limited power [9]. However intravenous ribavirin and convalescent plasma with a high neutralizing antibody titre are reported to be a useful treatment [5]. Oral ribavirin therapy has also been reported to be effective [10].

Afghanistan is located in the activity range of the Hyalomma tick and experiences the disease regularly. However, in 2008 the first multifocal outbreak was recorded in the country. The outbreak was detected in the Western Region of Afghanistan following trade of 8000 sheep and goats from the northern region of the country. The Western Region consists of 4 provinces of Herat, Badghis, Ghor and Farah (Figure 1). The total population of the western region is 3155600 . Herat is the largest province in this region with a population of 1642700 .

As this is the first multifocal outbreak detected in the Western Region of the country, it is very important to detect all cases and discover why the outbreak happened. Herat province is the second largest province in Afghanistan and borders 2 countries, the Islamic Republic of Iran in the west and Turkmenistan in the north, and other provinces of the country that lead to the main cities in the south of the country; it also acts as a meat supplier to the aforementioned areas. In particular, illegal trade of sheep and goats between Afghanistan, Islamic Republic of Iran and Turkmenistan is a threat to all 3 countries. Therefore a thorough outbreak investigation was necessary. The aim of this paper therefore is to report on the CCHF outbreak, the epidemiology of the disease and the control measures taken.

\section{Methods}

The first case of CCHF reported by the Disease Early Warning System (DEWS) was from Zindajan district of Herat on 10 July 2008. This case was found through passive surveillance. As a result, the system was sensitized and the case definition was sent to all health facilities so as to detect new cases of CCHF throughout the region. The rest of the cases were found through active case finding and surveillance in the affected districts. Demographic data and information on medical history, exposure history, treatment, contacts and travel history of all cases and contacts were collected. The team used the standard case definitions from World Health Organization sources [11,12].

Suspected case: Patient with sudden onset of illness with high-grade fever $>38.5^{\circ} \mathrm{C}$ for more than 72 hours and less than 10 days, especially in CCHFendemic areas and among those in contact with sheep or other livestock (shepherds, butchers and animal handlers).

Probable case: This was defined as follows.

- Suspected case with acute history of febrile illness $\leq 10$ days AND

- Thrombocytopenia $<50000 / \mathrm{mm}^{3}$ with any 2 of the following: petechial or purpuric rash, epistaxis, haematemesis, haemoptysis, blood in stools, ecchymosis, gum bleeding, other haemorrhagic symptom AND

- unknown predisposing host factors for haemorrhagic manifestations. 
Confirmed case: Probable case with positive diagnosis of CCHF in blood sample, performed in specially equipped high bio-safety laboratory, i.e.

- Confirmation of the presence of $\operatorname{IgG}$ or IgM antibodies to the CCHF virus in serum by enzyme-linked immunosorbent assay (ELISA)

- Detection of viral nucleic acid in specimen by polymerase chain reaction (PCR)

- Isolation of the virus.

\section{Results}

During the period 10 July to 22 October 2008, 30 cases of CCHF were found in 4 provinces of the Western Region of Afghanistan; 27 cases were detected in Herat province and 1 each in 3 other provinces of the region (Figure 1). The first case of CCHF reported by Disease Early Warning System (DEWS) was from Zindajan district of Herat on 10 July 2008. Cases were found in Sar-e-Hadira area of Herat city and Aliabad village of Karoukh district. Later on cases were found in Gulran, Guzara, Injil, Kohsan, Rabat Sangi, Obeh, Shindand and Torghonidi districts of Herat, and Farah Rood district of Farah, Shahrak district of Ghor and Jawand district of Badghis province (Figure 1).

Figure 2 show the epidemic curve indicating the peak around 20 August to 2 September. Based on epidemiological investigations, only 2 cases were secondary cases (a nurse and a family contact); the rest (28 cases) were primary

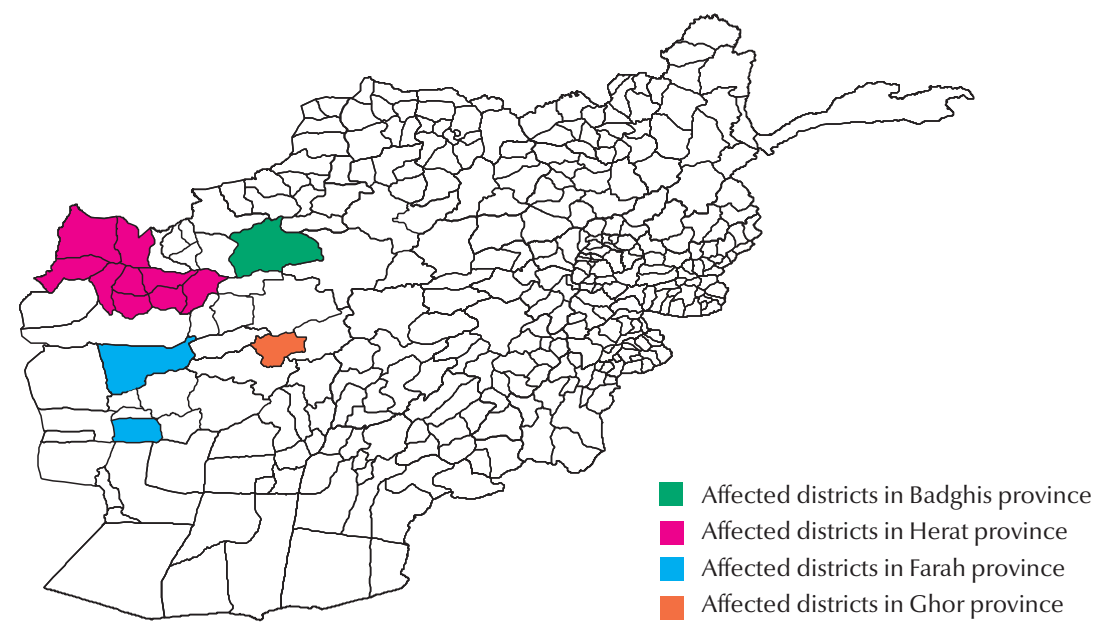

Figure 1 Map of districts affected by Crimean-Congo haemorrhagic fever, Afghanistan 2008

cases resulting from direct contact with animals or animal products.

Median age of the cases was 27 years with a range of $12-70$ years. The age category affected the most was the 18-55-year-olds, the productive age, and infection probably happened outside of the home (Table 1). As regards sex, $43 \%$ of the cases were female.

Most cases (93\%) presented to the hospital with fever, $83 \%$ with headache, $77 \%$ with body pain and $70 \%$ with epistaxis.

Treatment with ribavirin was started soon after diagnosis for 24 cases with a cure rate of $79 \%(P>0.0088)$. All patients received supportive therapy (e.g. transfusion of fresh blood, symptomatic treatment and treatment with tranexamic acid). The rest of the patients either did not come to the hospital or died before diagnosis. In all, 10 (33\%) cases died due to complications of the disease; 2 of the deaths were not registered in the hospitals but, according to their relatives, they fitted the case definition and were also living in the area where CCHF was found. Therefore the team decided to include them in the list of deaths.

A greater proportion of men died (41\%) than women (23\%) but the difference was not statistically significant $(P=0.29)$. The death rate was higher in butchers and housewives compared with other occupations (Table 2). More patients infected by contact with meat and body fluids died that those whose contact was through animal husbandry or ticks $(P=0.0048)$ (Table 2).

We also studied the association between signs and symptoms of disease at the time of admission to the hospital and outcome of disease. Only epistaxis was significantly associated with a higher frequency of death; $90 \%$ of cases who died in hospital had epistaxis at the time of admission $(P=0.021)$.

\begin{tabular}{|c|c|c|c|c|c|c|}
\hline \multirow[t]{2}{*}{ Age group (years) } & \multicolumn{2}{|c|}{ Males } & \multicolumn{2}{|c|}{ Females } & \multicolumn{2}{|c|}{ Total } \\
\hline & No. & $\%$ & No. & $\%$ & No. & $\%$ \\
\hline 12-18 & 2 & 6.7 & 2 & 6.7 & 4 & 13.3 \\
\hline 18-55 & 14 & 46.7 & 11 & 36.7 & 25 & 83.3 \\
\hline$>55$ & 1 & 3.3 & 0 & 0.0 & 1 & 3.3 \\
\hline Total & 17 & 56.7 & 13 & 43.3 & 30 & 100 \\
\hline
\end{tabular}




\begin{tabular}{|c|c|c|c|c|}
\hline Variable & Males & Females & Total & Mortality rate (\%) \\
\hline \multicolumn{5}{|l|}{ Age group (years) } \\
\hline $12-18$ & 0 & 1 & 1 & 10 \\
\hline $18-55$ & 7 & 1 & 8 & 80 \\
\hline$<55$ & 0 & 1 & 1 & 10 \\
\hline \multicolumn{5}{|l|}{ Occupation } \\
\hline Butcher & 2 & 0 & 2 & 20 \\
\hline Housewife & 0 & 3 & 3 & 30 \\
\hline Farmer & 1 & 0 & 1 & 10 \\
\hline Shopkeeper & 1 & 0 & 1 & 10 \\
\hline Cook & 1 & 0 & 1 & 10 \\
\hline Jobless & 1 & 0 & 1 & 10 \\
\hline Daily wage worker & 1 & 0 & 1 & 10 \\
\hline \multicolumn{5}{|l|}{ Type of contact } \\
\hline Meat and body fluids & 6 & 1 & 7 & 70 \\
\hline Animal husbandry & 0 & 1 & 1 & 10 \\
\hline Tick bite & 1 & 0 & 1 & 10 \\
\hline Unknown & 0 & 1 & 1 & 10 \\
\hline
\end{tabular}

All males who died were aged 18-55 years while there were deaths in females in all age categories. No children $<12$ years presented with the disease.

Of the 30 cases of CCHF, 33 close contacts were traced. All the contacts were examined and 3 were found positive for CCHF IgM but had no signs, symptoms or history of disease. All close contacts were family members, so all the positive contacts were family members. None of the contacts was treated and all of them survived.

\section{Measures implemented to control the outbreak}

An isolation ward was established 10 $\mathrm{km}$ from Herat city and full-time medical teams were assigned to take care of the patients. Specimens were collected from all suspected cases and contacts and examined by the Central Public Health Laboratory for confirmation.

Personal protective equipment, ribavirin and other medications and equipment for supportive therapy were provided to the clinicians. Universal and general infection prevention precautions were strengthened in the hospitals and health care facilities. The case definition was circulated to all health facilities in the regions and staff orientation was conducted in the regional and provincial hospitals.

Door-to-door health education campaigns and media campaigns were conducted in the affected villages, areas and provinces to inform people of the risks and how they can protect themselves against the disease. The health education campaign was undertaken with the support of the Provincial Health Director and Governor of Herat province. The same messages were broadcasted by television, radio and newspapers.

Infection prevention/control materials were distributed to the slaughter houses and illegal slaughter houses were all shut down by public health officials. Ruminants and their stables were decontaminated in the affected villages and areas.

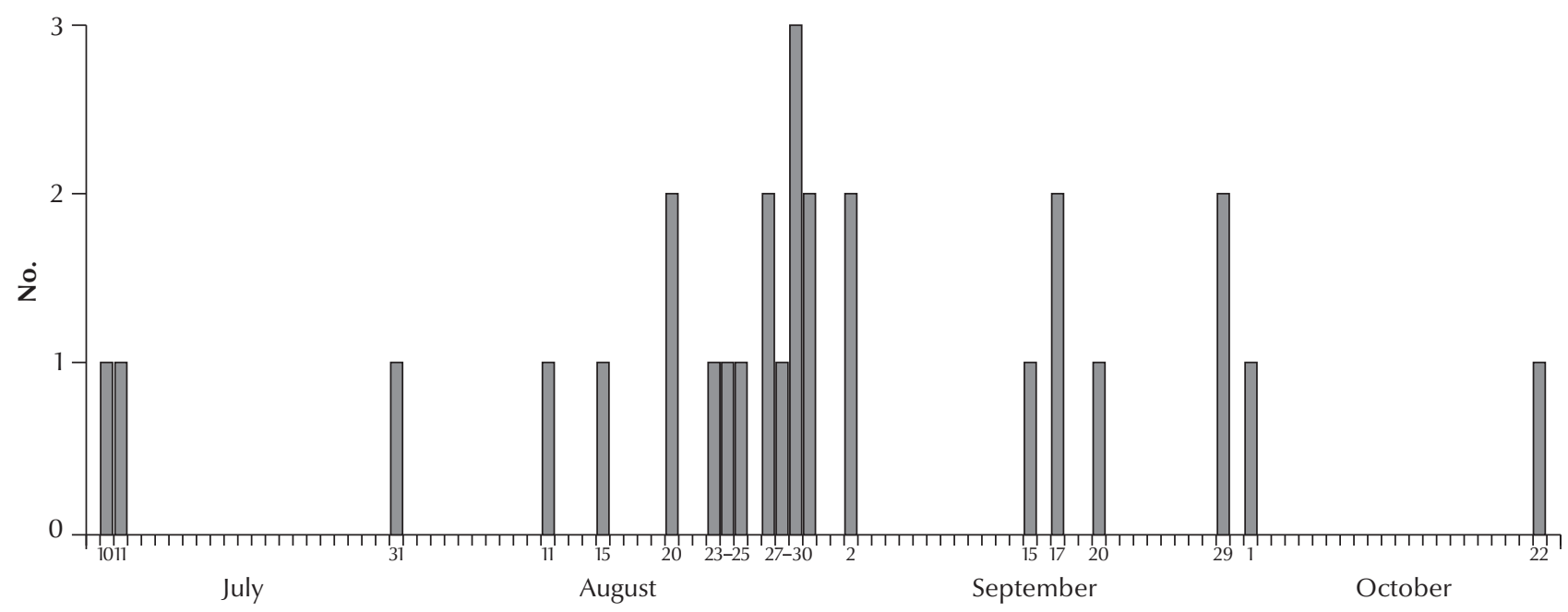

Figure 2 Epidemic curve of Crimean-Congo haemorrhagic fever outbreak in Western Region of Afghanistan,2008 


\section{Discussion}

During the first time multi-focal outbreak of CCHF in the Western Region of Afghanistan during July to October 2008, 30 cases were detected with a case fatality rates of $33 \%$. The outbreak affected 11 districts of Herat province and the districts of Farah Rood, Shahrak and Jawand in the 3 provinces of Farah, Ghor and Badghis.

The death rate was much higher in butchers and housewives. Butchers are routinely exposed to the blood and other body fluids of animals, which suggest exposure to higher doses of the virus. The high mortality in housewives could be due to 2 reasons: the first is that if slaughtering takes place in the house, housewives cleaning the house will be exposed to the blood and fresh meat, which generally happens in Afghanistan; the second reason is that if women are sick, the decision to take them to the doctor or hospital is often delayed, unless the onset of the disease is very severe, which led to the late admission of the women cases to the hospital and thus a greater risk of death

All cases and deaths were aged 12-70 years, but no cases of CCHF were found in children under 12 years of age although children in rural Afghanistan are the people who mainly who take care of animals in the pastures and fields; this may be due to cultural barriers and late presentation to hospital or it may be that children $<12$ years have some protection against the disease.

The collaborative action of different ministries, led by the Ministry of Public Health, resulted in quick control of the outbreak and the last case was reported on 22 October 2008. Furthermore early detection and diagnosis of the cases increased the chances of survival of the patients and protected health care workers from infections.

\section{References}

1. Wölfel $\mathrm{R}$ et al. Virus detection and monitoring of viral load in Crimean-Congo hemorrhagic fever virus patients. Emerging Infectious Diseases, 2007, 13(7):No.1097-1100.

2. Gonzalez JP et al. A fatal case of Crimean-Congo haemorrhagic fever in Mauritania: virological and serological evidence suggesting epidemic transmission. Transactions of the Royal Society of Tropical Medicine and Hygiene, 1990, 84(4):573-576.

3. Morrill JC et al. Serological evidence of Crimean-Congo haemorrhagic fever viral infection among camels imported into Egypt. Journal of Tropical Medicine and Hygiene, 1990, 93(3):201-204.

4. Crimean-Congo haemorrhagic fever. Geneva, World Health Organization, 2001 (WHO Fact sheet No. 208) (http://www. who.int/mediacentre/factsheets/fs208/en/index.html, accessed 25 March 2010).

5. Heymann DL. Control of communicable diseases manual, 19th ed. Washington DC, American Public Health Association, 2008:59-61.

6. Boon NA, Colledge NR, eds. Davidson's principle and practice of medicine, 20th ed. Oxford, Elsevier, 2006:310.
7. Kuljic-Kapulica N. [Emerging diseases. Crimean-Congo hemorrhagic fever]. Medikinski Pregled, 2004, 57(9-10):453-456 [In Serbian].

8. Ergonul O. Crimean-Congo haemorrhagic fever. Lancet Infectious Diseases, 2006, 6(4):203-214.

9. Soars-Weiser K et al. Ribavirin for Crimean-Congo hemorrhagic fever: systematic review and meta-analysis. BMC Infectious Diseases, 2010, 10:207.

10. McPhee SJ, Papadakis MA. Current medical diagnosis and treatment, 48th ed. New York, McGraw-Hill, 2009: 1231-1232.

11. Mofleh MJA, ed. Disease early warning system guidelines. Kabul, Afghanistan, Ministry of Public Health, 2008.

12. Communicable disease profile. Afghanistan and neighbouring countries. January 2002. Geneva, World Health Organization, 2002 (WHO/CDS/2002.7) (http://www.who.int/diseasecontrol_emergencies/toolkits/Afghanistan_profile.pdf, accessed 17 April 2012). 